\title{
The Effect of Agri-Environment Schemes on bees on Shropshire Farms
}

(1)

(1)

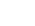

bLancaster Environment Centre, Lancaster University, Lancaster. LA1 4YW. crowthel@lancaster.ac.uk

\section{Abstract}

1. The decline of bees and other invertebrate pollinators is cause for global concern, with modern intensive agriculture identified as a key driver. Government-run agri-environment schemes (AES) have the potential to restore the local landscape to benefit bees.

2. Bee abundance, species richness and foraged plants were surveyed over a season on 18 farms in Shropshire, UK, classified into three treatment groups for comparison: Conventional, EntryLevel Stewardship AES (ELS), and Higher-Level Stewardship AES (HLS).

3. Bee abundance and species diversity were significantly higher on AES-compliant farms: there were only small or non-significant differences between ELS- and HLS-compliant farms.

4. ELS and HLS farms had higher diversity of floral foraging resources than conventionally managed farms. Cirsium, Heracleum sphondylium, and Rubus fruticosus were important resources for bees through the season.

5. Synthesis and applications. These results highlight that key ELS actions, such as set-aside of uncultivated field margins, hedgerow restoration, late-cut meadows and sowing of nectar-rich flower mixes, are effective AES options to improve the landscape for bee communities. Many plants considered agricultural weeds are important forage resources for bees.

\section{Keywords}

Agri-environment schemes, bees, ecosystem services, field margins, floral resources, pollination 
The intensification of agriculture over the past 50 years has led to the drastic decline of wildlife associated with British countryside (Kremen et al. 2002; Rundlof et al. 2008). Up to 50\% of species within Europe depend on agricultural ecosystems at some level, including threatened species (Stoate et al. 2009). The trade-off between local biodiversity and increases in yields has resulted in a ten-fold decline in economically and environmentally valuable taxa, many directly beneficial to agricultural production (Klein et al. 2007).

Two factors drive this decline: habitat loss and fragmentation (Rundlof et al. 2008; Bartlett et al. 2016), and the extensive use of agrochemicals (Carvell et al. 2007; Fijen et al. 2019). At field scales, farmland biodiversity is directly affected by alterations to farming practice, e.g. large fast-moving machinery, crop-rotation cycles and tillage systems (Holzschuh et al. 2006). With farmland making up more than $70 \%$ of the UK landmass (DEFRA, 2017: ), an increase in monoculture, lack of non-crop habitats and reductions in connectivity between semi-natural land have all contributed to drastic landscape alterations (Garrett et al. 2017).

Agriculture relies on ecosystem services to function and be productive. Such services that are provided by and contribute towards healthy, productive ecosystems include soil maintenance, nutrient cycling and pollination (Power, 2010). Intensive farming for high crop yields trade-off with ecosystem well-being, since it degrades the environment and associated services through increased soil erosion, nutrient removal and runoff, greenhouse gas emissions and environmental toxicity (Pamminger et al. 2018). Although ecosystem services are the underlying driver to production and environmental regeneration in agricultural systems, research suggests a significant lack of understanding from farmers about how directly land management can manipulate ecosystem services (Teixeira et al. 2018).

The UK Agri-Environment Schemes (AES), first implemented in the 1980s, aim to increase the recruitment of farmers into "wildlife-friendly" farming, encouraging alterations to management 
activities, reducing production intensity and promoting set aside of land (Pywell et al. 2006; Marja et al. 2019). Setting aside land should not be confused with abandonment; set-aside requires management to increase biodiversity (Firbank et al. 2003). The two main levels of Countryside Stewardship AES are administered by Natural England, Department for Environment Food and Rural Affairs (DEFRA), and the Rural Payments Agency. Entry-level Stewardship (ELS) is a widespread and flexible scheme (this scheme was replaced with the Mid-Tier scheme during 2018). Higher-level Stewardship (HLS) is a more complex scheme, targeting specific natural elements within farmland landscapes and requiring stronger commitment to changing land management methods and losing cultivatable land (Baker et al. 2012). Farmer obligations within these schemes encompass adherence to wildlife-friendly and environmentally friendly actions aimed at promoting species diversity, restoring wildlife populations and enhancing/maintaining natural resources (Carvell et al. 2007; Hardman et al. 2016a).

Assessing the effectiveness of AES is difficult due to complex interactions between biotic environmental components, landscape heterogeneity and differing land management practices among sites (Scheper et al. 2013; Holland et al. 2015; Marja et al. 2019). Since the introduction of such schemes, several reviews have quantified effectiveness. The results are mixed but suggest an overall increase in biodiversity (Whittingham, 2011; Batary et al. 2015). Agri-environment schemes are beneficial to farmland birds (Kleijn et al. 2011; Westbury et al. 2017), plants (Carvell et al. 2007; van Klink et al. 2017), mammals (Broughton et al. 2014) and some invertebrate groups (FuentesMontemayor et al. 2011; Hof \& Bright, 2010).

With pollination becoming prominent in conservation efforts in recent years (Larson et al. 2017; Wilson, Forister \& Carril, 2017), specific actions have been introduced to the AES to benefit pollinators. Set-aside of uncultivated land is known to produce significant benefits to insect pollinators (bees, flies, and butterflies: Raymond et al. 2014; Hardman et al. 2016b), promoting the abundance and diversity of perennial plants and increasing flower densities (Stoate et al. 2009). Additional 
pollinator-specific actions include mixes of nectar-rich flower species, creation of low-input grasslands (Scheper et al. 2013), enhanced grassland buffer strips, non-rotational grassland strips, and creation/preservation of species-rich grasslands (Wood et al. 2015; Hardman et al. 2016a). These actions highlight the need for landscape heterogeneity and a variable habitat matrix to provide seasonal support for pollinators (Stoate et al. 2009; Breeze et al. 2014). The current demand for crop pollination surpasses the abilities of domesticated Apis mellifera and Bombus terrestris, and thus the pollination efforts of wild bees have become increasingly important (Breeze et al. 2014; Hardman et al. 2016a). A recent study found that honeybee presence has a negative influence on wild bee abundances through transmission of diseases and direct competition for floral resources (Fijen et al. 2019). Holzschuh et al. (2012) conclude that wild bees can be more efficient at pollinating certain crops than honeybees. This difference could be down to solitary bees and bumblebees having efficient pollen deposition (e.g. buzz pollination), different physiology and phenology, and greater pollen exchange.

Apis mellifera and several common Bombus species are well studied, but these make up a small percentage of the total British bee fauna: most bees are solitary and relatively poorly studied (Wood, Holland \& Goulson, 2017). Unlike Apis mellifera, bumblebees and solitary bees do not store pollen and nectar for extended periods of time, and thus can suffer greatly from gaps in resources over time (Carvell et al. 2015). Management options reduce such gaps are positive aspects of the AES (Rundlof et al. 2008; Wood et al. 2015).

For wild bees, the abundance, timing, and diversity of floral resources are significant factors limiting densities (Scheper et al. 2013; Carvel et al. 2015; Hardman et al. 2016a). Holzschuh et al. (2016) comment on the need for knowledge of the temporal dynamics of bee communities, specifically regarding insect-pollinated crops, highlighting the differences in crop prices, subsidies and rotation methods. Many of the traits and niches of wild bees are little understood, but there are 
marked differences among species in foraging range, season length, nesting position and tongue length - a crucial indicator of the feeding niche (Goulson \& Darvill, 2004; Wood et al. 2015).

This study investigates the effectiveness and viability of agri-environment schemes in terms of pollinator conservation and resource provisioning. The following directional hypotheses are tested; i) AES-compliant farms have significantly higher bee abundance and support a greater number of bee species, ii) AES-compliant farms supply significantly greater flowering plant diversity to act as forage resources. The focus is on bee and flower communities found within field-margin habitats in agricultural landscapes. The study compares Apis, Bombus and solitary-bee species among Conventional farms and the two levels of AES, identifying any specific actions within the AES levels that provide benefits to local bee communities.

\section{Methodology}

\subsection{Study sites}

18 farms were surveyed between April and September 2018 in Shropshire, England. All were based within or around the Shropshire Hills Area of Outstanding Natural Beauty (AONB: see Fig. 1). Farms were chosen to fit one of three treatment categories: Conventional (C: seven farms selected), EntryLevel (ELS: five farms selected) and Higher-Level schemes (HLS: six farms selected). All management techniques implemented on farms enrolled in AES adhered to DEFRA guidelines and complied with Natural England environmental regulations (full details are in Table S1). The weather in the 2018 survey season was unusually hot and dry during midsummer, and this may have influenced bee activity and the longevity of floral resources.

Farms within treatment groups were separated into two approximately equal sets to be surveyed on alternate weeks. Due to differences in landscape heterogeneity and phenological differences, it was not possible to match farms into triplets, one of each treatment. Instead, farms were selected to represent the land-management composition within the region to try to represent farming practices and habitats across the AONB. Four farm types were included: arable (cereal/bean), 
livestock-arable mixed, livestock-based (cattle and sheep) and dairy. However, farms were not specifically selected based on type, resulting in slight differences among treatment groupings. Livestock-based and livestock-arable mixed were the most frequent farm types, with six livestockbased farms (four conventional, two HLS), and seven livestock-arable mixed farms (two conventional, four ELS and one HLS). There were three arable farms (one ELS, two HLS), and two dairy farms (one conventional, one HLS) (see Table S1). management and environment of each farm (for full answers see Table S1).

Bombus, Apis mellifera and solitary bees were surveyed utilising a transect method adapted from standard butterfly surveys (Pollard, 1977). A total of one kilometre of belt transects was established along typical field-margin habitats (hedgerow, stream, or ditch) of two to three fields on each farm. Fields were selected to be as far apart as possible (greater than $5 \mathrm{~km}$ ) to reduce population overlap, but at smaller farm locations this remained a slight possibility. Start points were selected along fieldmargin habitats with margins internal to the farm, not along roadsides, and excluding the first 10 metres from the field entrance. Transects were approximately two metres wide, including the fieldmargin habitats (estimated to be one metre) and one metre of uncultivated field margins (or cultivated land where there were no margins in place). Observations/captures were made up to a height of two metres, between 10.00 and 17.00 on days with acceptable weather conditions (local air temperatures above $13^{\circ} \mathrm{C}$, minimum $60 \%$ clear sky and no rainfall: Pywell et al. 2006). Each farm within the three treatment groups was selected at random to be surveyed within specific time slots, rotating morning (10:00-12:00), early-afternoon (12.30-14:30) and late-afternoon (15:00-17:00) to reduce the effect of any potential fluctuations in bee abundance over the day. 
queens, workers, or males. To minimise multiple recordings of specimens, bees identified to species on sight were monitored until they left the transect. Bees that could not be immediately identified were caught in a net, identified, and released (these bees left the transect as a result), or caught and retained for identification. Following the transect survey, a sweep net survey was conducted along the same belt transect, specifically to target solitary bee species, sweeping horizontally across the ground of the field margins and vertically along the vegetation face of the margin habitat itself. Specimens were identified at the end of the survey using the keys in Falk (2015) and verified using the local atlas (Jones \& Cheeseborough, 2014). The bee names follow Falk (2015), except Bombus terrestris and Bombus lucorum agg., which were recorded collectively as B. terrestris/lucorum agg. because reliable vegetation, the flower species were recorded to genus or species level where possible.

\subsection{Data analysis}

The summary data were the counts of the number of individuals of each bee species summed for each farm and for each treatment group, together with some summaries at generic level (Andrena, Bombus, Lasioglossum, and Nomada). The flower species used by bees were recorded, together with the numbers of each bee species seen foraging on them.

To test the effect of the AES schemes on bee abundance and species diversity, for each survey the total abundance of all bees, and the three standard indices of diversity (Hill numbers: Chao et al. 2014) were calculated: HO is simply species richness, which emphasizes rare species because these count however rare they are; $\mathrm{H} 1$ is the average number of common species because it is weighted by abundance; $\mathrm{H} 2$ is the average number of abundant species because it puts even more weight on relative abundance. These three indices capture much of the relative abundances of the community (Chao et al. 2014). The Hill numbers formed the response variables in generalised linear mixed models (due to the use of repeated measures [random factors] of individual farm and survey date) to be able to see the influence of the AES treatments on bee abundance and species diversity. Residuals were 
checked and the default normal errors were appropriate for all analyses. All models included random factors of farm and date, and the fixed predictors of AES group, farm type, and the AES $\mathrm{x}$ type interaction, tested by ANOVA. A priori contrasts were applied within each ANOVA, predicting that Conventional farms would have lower bee abundance and species diversity than farms managed under either AES $(C<E L S+H L S)$ and that ELS farms would have a lower bee abundance and species diversity than HLS farms (ELS < HLS). In addition, data for bumblebee species were analysed separately. All analyses were conducted with R version 3.5.1 (R Core Team, 2018) using the package Ime4.

Data for the genus Bombus were analysed separately due to the large amount of information collected, including the subgenus Psithyrus. Some Bombus species were present on all surveyed farms, including both common and rare species, as well as generalist and more specialised species, making this sub-analysis worthwhile. Bombus species are now actively being utilised and manipulated as commercial crop pollinators (e.g. B. terrestris), and hence a greater insight into the effect of farm management may promote better monitoring and conservation.

Floral diversity was estimated by counting the flowers utilised by foraging bees; means were used to allow for differences in sample sizes among treatment groups. Summing over all transects, the flower $\mathrm{x}$ bee matrix of total numbers of visits was formed, and the interactions plotted as community network diagrams using the bipartite package in R (Dormann, Gruber \& Fruend, 2008). The timecourse of the most-used flowers across the survey season highlighted any temporal gaps in forage.

\section{Results}

\subsection{Bee abundance and diversity}

A total of 4234 individual bee sightings were recorded over the study period (674 Apis mellifera, 2130 Bombus spp. and 1430 solitary bees). 1055 bee sightings occurred on Conventional farms, 1407 sightings on ELS and 1772 sightings on HLS (Fig. 2a). 65 species of 12 genera were identified, with a combined total of 44 species identified on Conventional farms, 47 on ELS and 50 on HLS (Fig. 2b; 
Supporting information Table S2). The records included species locally scarce to Shropshire, such as Melecta albifrons and Lasioglossum malachurum. Overall species richness differed between farm treatments; Conventional farms ranged from 16 to 24 species between farms, ELS farms between 26 and 33, and HLS farms between 19 and 35.

The 15 most common species (Fig. 3) included seven Andrena spp., six Bombus spp., Apis

204

mellifera and Halictus rubicundus. In terms of total sightings, the most species-rich genera were Andrena (16 species), Lasioglossum (14 species), Bombus (11 species) and Nomada (11 species). The genera with the greatest abundances were Bombus (2130 sightings), Andrena (933) and Apis (674). The most abundant Andrena were A. nigroaenea, A. haemorrhoa, and A. chrysosceles; for Lasioglossum they were L. calceatum and L. leucopus; for Bombus, B. terrestris/lucorum agg., B. lapidarius and B. pascuorum; and for Nomada, N. goodeniana and N. lathburiana. The three most common species overall (See Fig. 3 and Fig. 4) were Apis mellifera (674 sightings), B. terrestris/lucorum agg. (632 sightings), and B. lapidarius (606 sightings). A total of 11 Bombus species out of the 18 recorded in Shropshire (Jones \& Cheeseborough, 2014) were identified across all the study farms. Five species were present on every farm; Bombus terrestris/lucorum agg., B. lapidarius, B. pascuorum, Apis mellifera, and Andrena haemorrhoa.

Bee phenology varied amongst species: Bombus spp. and Apis mellifera were present throughout the entire study period, appearing in every week of surveying in varying abundances (Fig. 4a, b, c). Bombus (Psithyrus) spp. were present only on farms where the associated host was present, appearing in low numbers during April - May and throughout August. Andrena spp. appeared early on in relatively high numbers (Fig. 4d), but these started to drop in late July, with no sightings into August. Nomada spp., kleptoparasites of Andrena, also appeared early on alongside their host species, with sightings occurring from April until June (Fig. 4f). Halictus and Lasioglossum were present sporadically until July when their abundances increased until the end of the survey period. Numbers of $H$. rubicundus increased during August (Fig. 4e), after appearing in low abundance throughout the survey 
period. The numbers of Sphecodes spp. fluctuated in association with their hosts (Andrena, Halictus, and Lasioglossum), appearing when their various host abundances peaked. An individual Melecta albifrons was identified, but its host, Anthophora plumipes, was not recorded, although common in gardens throughout the local area.

\subsection{Differences among AES treatments}

Bee abundance and diversity per survey were found to be significantly related to land management under AES (Fig. 5; Supporting information Table S3). Using either AES treatment had a significant positive influence compared to Conventional farms on the number of bees and all the measures of diversity, $\mathrm{HO}, \mathrm{H} 1$, and $\mathrm{H} 2$. The first contrast $(\mathrm{C}<\mathrm{ELS}+\mathrm{HLS})$ was always highly significant $(p<<0.001$ : see Supporting information Table S3). Compliance with either AES showed the greatest influence on abundance (Fig. 5a) and species richness (Fig. 5b), indicating that the largest effect was on rare species. The smallest effect was found on H1 (Fig. 5c), which emphasizes common species. The second contrast (ELS $<$ HLS) was not in the predicted direction for any of the Hill numbers (and hence not significant), but there was a small increase in overall bee abundance for HLS (Fig. 5; Supporting information Table S3). Farm type showed no significant effects on any of the response variables (Supporting information Table S3). However, there were significant or near-significant interactions between AES and farm type for all response variables ( $p=0.011-0.019$ : see Supporting information Table S3; Fig. S1). Species richness $(\mathrm{HO})$ showed the most significant response to the AES $\mathrm{x}$ farm type interaction (Supporting information Fig. S1), where the difference between Conventional and HLS farms is smaller in Livestockbased farms than in other types of farm.

For just the bumblebees, the AES treatment had significant effects on abundance and HO (species richness), but not $\mathrm{H} 1$ or $\mathrm{H} 2$, both of which place emphasis on common species (Supporting information Table S4). For abundance and HO, again there was a highly significant first contrast (C< ELS+HLS; $p<<0.001$ ), but no effect for the second contrast (ELS $<$ HLS). Farm type and the interaction between AES and farm type showed no significant influence on the bumblebee community. 
250

251

252

Bees were recorded utilising 62 flowering plant species across all study sites throughout the season, with 36 used on Conventional, 40 on ELS and 39 on HLS farms. Mean counts showed species diversity remained highest in ELS-compliant farms (see Fig. 6). Species counts on conventional farms ranged from five to 16 species, from 14 to 18 on ELS-compliant farms, and 10 to 18 on HLS-compliant farms. The most dominant flowers being used included Crataegus monogyna, Taraxacum spp., Heracleum sphondylium, Trifolium pratense, Trifolium repens, Rubus fruticosus and Cirsium spp (Fig. 7). Impatiens glandulifera (Himalayan Balsam, an aggressive invader) occurred on two farms where it acted as a significant late-season nectar source (Supporting information Fig. S2), attracting many foraging Bombus spp. and Apis mellifera.

\section{Discussion}

Both Entry-level and Higher-level stewardship AES were found to influence significantly the abundance and species diversity of bees, with higher numbers of bees and greater species diversity seen on AES-compliant farms. This difference in bee abundance and diversity cannot solely be attributed to AES due to the differences between farming landscapes, although general inferences can be made from the results. Conventional and AES-compliant farms alike produce the environmental conditions to support common species, such as the six common bumblebees (including B.terrestris, B. lapidarius and B. pascuorum) and Apis mellifera (Hanley \& Wilkins, 2015). Fijen et al. (2019) show that floral visits are dominated by a small number of species with the ability to exploit mass flowering crops and make a significant contribution to crop pollination. This would suggest that the small collection of species consistently found on all farms, including Conventional, could provide most crop pollination services. Although, each visit should not be considered a successful pollination event, it is likely that more bees lead to more flower visits, which equates to a greater pollination services.

The treatment group that produced the most variable results was HLS, with species diversity ranging from 19 to 35 species across the treatment group. This larger variation in species diversity 
among HLS sites could be due to management actions on these farms varying greatly. Conventional farms consistently showed the lowest abundances and lowest species diversity. This highlights the significant lack of appropriate habitats for feeding and nesting resources. Likewise, AES-compliant farms supported more flowering plant species recorded as being utilised, providing bees with a greater variety of forage resources than conventionally managed farms, and suggesting greater habitat diversity.

The results in number of bees and species diversity mirror the results found in similar research; Woods et al. (2016) found 105 species across 19 AES-compliant farms with 3km transects, exhibiting a similar array of groups, including a number of Psithyrus spp. and parasitic solitary species. Similarly, Rundlof et al. (2008) identified 11 bumblebee species across 12 matched pairs of organic and conventional farms, finding significantly more species in organic heterogeneous landscapes than conventional.

\subsection{Agri-environment schemes and landscape context}

HLS farms can often focus actions on specific areas of interest, such as woodland, in conjunction or instead of field-level actions (i.e. set aside margins). In comparison, one of the most common ELS actions is land set-aside as field margins (see Table S1). Since ELS farms supported the most diverse bee communities, this suggests that this is more likely to establish favourable environments. This highlights the fact that actions spread across the landscape at field-level could be more beneficial than focusing on specific areas of interest (land sharing vs land sparing; Kremen, 2015). The greater bee abundance on HLS-compliant farms suggests that these can support the level of resources needed to allow bee populations to be sustained at high levels. Pollinator abundance and diversity can decrease with increasing distance from semi-natural habitat (Gill et al. 2016), emphasizing that the spatial structure and configuration of AES actions across the landscape is essential for bee conservation and efficient pollination services (Holland et al. 2015).

Field margins provide foraging resources and refuge habitats at field-level, increasing connectivity between semi-natural, non-cultivated habitats throughout the local landscape 
299 (Holzschuh et al. 2006). This habitat connectivity within the agricultural landscape specifically benefits bumblebees and solitary bees through access to seasonally variable forage. In addition to habitat corridors, hedgerows can act as environmental buffers, reducing the spread of agrochemicals (Carvell et al. 2007; Hanley and Wilkins 2015). The positive influences derived from the management of noncrop field margins are likely due to the increase in the availability of flowering plant species, which acts as a key determinant to bee reproductive success (Pywell et al. 2006; Carvell et al. 2015).

\subsection{Pollinator-targeted actions}

Farms that supported a high abundance and species diversity of bees adhered to several similar AES actions, such as sowing and management of nectar and pollen-rich flower mixes (see Table S1). These mixes generally include several legume species and species of tussock grasses, providing both forage and nesting resources (Carvell et al. 2007; Holzschuh et al. 2012). These mixes flower in late summer (see Fig. S2), failing to supply resources early in the season when bumblebee colonies begin establishment. Garibaldi et al (2014) emphasize that creation of set-aside field margin is effective at providing resources that support bee communities. The success of this option can be dependent on how long the margin has been established, with the appearance of Cirsium increasing the abundance of several Bombus spp. (Carvell et al. 2007). Overspill of pollination services from such margins proves beneficial to crops (Carvell et al. 2015).

The option of hedgerow creation and restoration was taken up on several HLS-compliant farms. Hedgerow restoration and the creation of dense, species-rich hedgerows have been linked to a marked increase in biological diversity (Staley et al. 2015). Hedgerows are valuable habitats for pollinators within agricultural landscapes, and their creation and optimal management can increase pollination services, benefiting crop production (Garrett et al. 2017). Hedgerows provide shelter and forage resources for bees because they host several woody plants and flowers adapted to woodlandedge conditions not found in grassland habitats and on cultivated land (Wratten et al. 2012). Management practice is a significant limiting factor to the success of hedgerows in increasing 
biodiversity because they need to connect and have structural integrity: both over-trimming and neglect in management reduce biodiversity (Staley et al. 2015).

\subsection{Forage provisioning}

The diversity of flowering plants varied amongst the farms, with those managed in compliance with ELS having the highest species diversity, followed by HLS farms. Most field margins managed in ELS are low-input, self-regenerating margins, with the dominant flowering plant species being Cirsium arvense, Cirsium vulgare, Heracleum sphondylium and Rubus fruticosus. These species are rapid colonisers (Pywell et al. 2006) and occurred on farms of all treatment groups. Forage provision acts as a limiting factor on local bee populations and loss of floral diversity in conventionally managed agricultural landscapes is a prominent driver in bee declines (Dicks et al. 2015; Carevll et al. 2015). Marja et al (2019) showed that effective AES focus first on the availability of food resources to enhance pollinator diversity. Greater amounts of semi-natural habitats aid bees through providing resources during time between short mass-flowerings of crop (Holzschuh et al. 2012).

From the data, the intentional sowing of field margins appeared to be successful in increasing the abundance and diversity of bees. Specific species sown on ELS and HLS farms include Sinapis arvensis, Phacelia tanacetifolia, Trifolium repens, and Melilotus officinalis, all known to attract bees, especially Apis mellifera.

The time-course of foraging bee at flowers (Fig. A2) showed a decline in mid-May, whilst the abundances of the commonly seen species (Fig. 4) did not reflect this decline in sightings. This suggests that there is a gap in the diversity of flowering plants used for foraging at this time. Crataegus monogyna and Taraxacum spp. were the dominant flowering plants initially utilised the beginning of the season. Resources at this time in the season are essential for emerging solitary bees and Bombus queens to begin nesting (Devoto et al., 2013). Alterations to land management methods can help to alleviate this resource gap via less-intense cutting or not cutting in the previous autumn/winter selected areas of hedgerows where C. monogyna is dominant. Impatiens glandulifera was identified 
as an important late-season nectar source, providing resources when many flowering plant species have gone to seed. This invasive plant may have displaced native flowers, actually reducing the diversity of nectar and pollen sources throughout the entire season (Flugel, 2017).

\subsection{Implications for agri-environment schemes}

This study confirms that the implementation of AES, both at entry and higher levels, could mitigate the influences of modern intensive farming to allow a larger and more complex bee community to be supported. The findings specifically highlight the effectiveness of ELS, under which approximately $60 \%$ of UK agricultural land is registered (Carvell et al. 2015), showing that this level of scheme can effectively supply the resources needed to support more bees of more species than conventional farming. Encouraging the uptake of low input but effective options could encourage the more widespread adoption of AES. Research suggests that conservation schemes are most effective in simple, homogeneous landscapes, and therefore efforts in areas of intensive agriculture have a high potential for success due to the large ecological contrast (Garratt et al. 2017; Marja et al 2019). Farm size may also play a role in determining the community composition of bees and floral resources. Larger AES-compliant farms with high landscape heterogeneity may provide more resources than smaller similarly managed farms (Rundlof et al. 2008). In this study, HLS farms averaged the largest in size (340 acres), followed by ELS (180 acres). Integrating a larger farm into an AES may be more worthwhile in terms of financial compensation and area of land to spare from production. With conventional farm size averaging around 70 acres, the influence of the wider landscape may be greater than on larger farms, whether positive through increasing wider landscape heterogeneity, or negative.

Based on the effectiveness of AES shown in this case, the future of agricultural management requires trade-offs between agriculturally viable land in favour of the preservation of ecosystem services such as pollination, biocontrol, and nutrient cycling (Hardman et al. 2016a; Marja et al. 2019). Taking agricultural land out of production does not appear economically advantageous at first, but the additional pollination services can increase crop pollination through overspill (Carvell et al. 2015). Set 
aside of productive land also reduces the area of land exposed to agrochemicals. Herbicides have been found to impact bees negatively in a myriad of ways, reducing sperm counts and worker survival, and hindering larval development (Belsky \& Joshi, 2020). Glyphosate, a known stressor for honeybee larval development that reduces bumblebee and solitary bee longevity (Vazquez et al. 2018; Belsky \& Joshi, 2020), was a commonly used herbicide. Other pesticides used included Lambda-Cyhalothrin, which has negative implications on bees learning and memory (Liao et al. 2018), Pyrethroids, which induce a myriad of detrimental effects on honeybees at tissue and cellular levels (Kadala et al. 2019)

The findings of this study also recommend tolerance of flowers currently considered agricultural weeds, such as Heracleum sphondylium, Rubus fruticosus, and Cirsium (Gabriel \& Tscharntke 2007; Bretagnolle \& Gaba 2015). Preservation of flowering plants in uncultivated habitats supports bee communities, specifically opportunistic pollinators (Fijen et al. 2019), between periods of massflowering of crops, keeping pollinators within the landscape for their services. Understanding crop economic thresholds for weed tolerance could allow these pollinator-friendly species to be incorporated into seed mixes without negatively affecting crop yield. They could be the only resource available at a crucial time of low floral resources and are perhaps not best-suited to the needs of bees. Genissel et al. (2003) state that Taraxacum has low nutritional value, limiting larval success in Bombus terrestris and hence resulting in low fitness. However, Wood et al. (2017) showed that sown floral resources may be not recognised as resources by solitary bees, which instead rely on plants in the wider environment. The limitations of this study should be considered when reviewing its results. Agrochemical applications could not be controlled on these active commercial farms over the period of study, and may have had an influence on the results. Additionally, as with many bee-related studies, it is difficult to foresee and control the influence of honeybees on local wild bee populations (Mallinger et al. 2017).

\section{Conclusion}


The current broad agri-environment schemes do have the ability to produce environmental conditions that supply the resources needed to promote abundant and diverse bee communities within agricultural landscapes. Bee abundance and species diversity were positively influenced by AES options, such as the creation of non-crop field margins, hedgerow restoration, late-cut meadows and the sowing of nectar-rich flower mixes. The most widely used level of agri-environment scheme, ELS, has the ability to increase significantly the abundance and diversity of bee species with relatively low input from farmers. This study also identifies the value of flowers currently considered agricultural weeds to foraging bees through the year, highlighting the need for a shift in opinion about their removal. Keeping them will benefit bee communities.

\section{Acknowledgments}

Thank you to landowners and farmers for permission to access study sites and assistance in providing information.

Funding: This research was funded by the Shropshire Hills AONB Conservation Fund and The Millichope Foundation.

\section{References}

Baker, D. J., Freeman, S. N., Grice, P. V. and Siriwardena, G. M. (2012). Landscape-scale responses of birds to agri-environment management: A test of the English Environmental Stewardship scheme. Journal of Applied Ecology. 49(4), 871-882. doi:10.1111/j.1365-2664.2012.02161.x

Bartlett, L. J., Newbold, T., Purves, D. W., Tittensor, D. P. and Harfoot, M. B. J. (2016). Synergistic impacts of habitat loss and fragmentation on model ecosystems. Proceedings of the Royal Society B: Biological Sciences. 283(1839). doi:10.1098/rspb.2016.1027

Batary, P., Dicks, L. V., Kleijn, D. and Sutherland, W. J. (2015). The role of agri-environment schemes in conservation and environmental management. Conservation Biology. 29(4), 1006-1016. doi.:10.1111/cobi.12536 
Belsky, J. and Joshi, N. K. (2020). Effects of Fungicide and Herbicide Chemical Exposure on Apis and Non-Apis Bees in Agricultural Landscape. Frontiers in Environmental Science. 8(81). Doi: 10.3389/fenvs.2020.00081

Breeze, T., Bailey, A., Balcombe, K., and Potts, S. (2014). Costing conservation: an expert appraisal of the pollinator habitat benefits of England's entry-level stewardship. Biodiversity and Conservation. 23(5), 1193-1214. doi:10.1007/s10531-014-0660-3

Bretagnolle, V. and Gaba, S. (2015). Weeds for bees? A review. Agronomy for Sustainable Development. 35(5), 891-909. doi:10.1007/s13593-015-0302-5

Broughton, R. K., Shore, R. F., Heard, M. S., Amy, S. R., Meek, W. R., Redhead, J. W., Turk, A. and Pywell, R. F. (2014). Agri-environment scheme enhances small mammal diversity and abundance at the farm-scale. Agriculture, Ecosystems \& Environment. 192(1), 122-129. doi:10.1016/j.agee.2014.04.009

Carvell, C., Meek, W. R., Pywell, R. F., Goulson, D. and Nowakowski, M. (2007). Comparing the efficacy of agri-environment schemes to enhance bumble bee abundance and diversity on arable field margins. Journal of Applied Ecology. 44(1), 29-40. doi:10.1111/j.1365-2664.2006.01249.x

Carvell, C., Bourke, A. F. G., Osbourne, J. L. and Heard, M. S. (2015). Effects of an agri-environment scheme on bumblebee reproduction at local and landscape scales. Basic and Applied Ecology. 16(6), 519-530. doi:10.1016.j.baae.2015.05.006

Chao, A., Gotelli, N. J., Hsieh, T. C., Sander, E. L., Ma, K. H., Colwell, R. K. and Ellison, A. M. (2014). Rarefaction and extrapolation with Hill numbers: a framework for sampling and estimation in species diversity studies. Ecological Monographs. 84(1), 45-67. doi:10.1890/13-0133.1

DEFRA (Department for Environment, Food and Rural Affairs) (2017). Farming Statistics: Final crop areas, yields, livestock populations and agricultural workforce. https://assets.publishing.service.gov.uk 
Devoto, M., Bailey, S. and Memmott, J. (2013). Ecological meta-networks integrate spatial and temporal dynamics of plant-bumble bee interactions. Oikos. 123(6), 714-720. doi:10.1111/j.1600-0706.2013.01251.x

Dicks, L. V., Baude, M., Roberts, S. P. M., Phillips, J., Green M. and Carvell, C. (2015). How much flowerrich habitat is enough for wild pollinators? Answering a key policy question with incomplete knowledge. Ecological Entomology. 40(1), 22-35. doi:10.1111/een.12226

Dormann, C.F., Gruber B. and Fruend, J. (2008). Introducing the bipartite Package: Analysing Ecological Networks. $R$ News. 8(2): $8-11$

Downing, E. and Sutherland, N. (2017). The UK bee population: Debate pack. House of Commons Library. Number CDP 2017/0226. researchbriefings.files.parliament.uk

Falk, S. (2015). Field guide to the bees of Great Britain and Ireland. London: Bloomsbury Wildlife.

Firbank, L. G., Smart, S. M., Crabb, J., Critchley, C. N. R., Fowbert, J. W., Fuller, R. J., Gladders, P., Green, D. B., Henderson, I. and Hill, M. O. (2003). Agronomic and ecological costs and benefits of setaside in England. Agriculture, Ecosystems \& Environment. 95(1), 73-85. doi:10.1016/S01678809(02)00169-X

Flugel, H. J. (2017). The Himalayan balsam (Impatiens glandulifera) - threat or enrichment? Natur und Landschaft. 92(6), 268-273.

Fijen, T. P. M., Scheper, J., Boekelo, B., Raemakers, I. and Kleijn, D. (2019). Effects of landscape complexity on pollinator are moderated by pollinators' association with mass-flowering crops. Proceedings of the Royal Society B: Biological Sciences. 286(1900). doi:10.1098/rspb.2019.0387

Fuentes-Montemayor, E., Goulson, D. and Park, K. J. (2011). The effectiveness of agri-environment schemes for the conservation of farmland moths: assessing the importance of a landscape- 

2664.2010.01927.x

471

Gabriel, D. and Tscharntke, T. (2007). Insect pollinated plants benefit from organic farming. Agriculture, Ecosystems \& Environment. 118(1-4), 43-48. doi:10.1016/j.agee.2006.04.005

Garibaldi, L. A., Carvalheiro, L. G., Leonhardt, S. D., Aizen, M. A., Blaauw, B. R., Isaacs, R., Kuhlmann, M., Kleijn, D., Klein, A. M., Kremen, C., Mmorandin L., Sheper, J. and Winfree, R. (2014). From research to action: enhancing crop yield through wild pollinators. Frontiers in Ecology and the Environment. 12(8), 439-447. doi:10.1890/130330

Garratt, M., Senapathi, D., Coston, D., Mortimer, S. and Potts, S. (2017). The benefits of hedgerows for pollinators and natural enemies depends on hedge quality and landscape context. Agriculture, Ecosystems \& Environment. 247(1), 363-370. doi:10.1016/j.agee.2017.06.048

Genissel, A., Aupinel, P., Bressac, C., Tasei, J. N. and Chevrier, C. (2003). Influence of pollen origin n performance of Bombus terrestris micro-colonise. Entomologia Experimentalis et Applicata. 104(2-3), 329-336. Doi: 10.1046/j.1570-7458.2002.01019.x

Goulson, D. and Darvill, B. (2004). Niche overlap and diet breadth in bumblebees; are rare species more specialized in their choice of flowers? Apidologie. 35(1), 55-63. doi:10.1051/apido:2003062

Hardman, C. J., Norris, K., Nevard, T. D., Hughes, B. and Potts, S. G. (2016a). Delivery of floral resources and pollination services on farmland under three different wildlife-friendly schemes. Agriculture, Ecosystems \& Environment. 220(1), 142-151. doi:10.1016/j.agee.2016.01.015

Hardman, C. J., Harrison, D. P. G., Shaw, P. J., Nevard, T. D., Hughes, B., Potts, S. G. and Norris, K. (2016b). Supporting local diversity of habitats and species on farmland: A comparison of three wildlife-friendly schemes. Journal of Applied Ecology. 53(1), 171-180. doi:10.1111/13652664.12557 
Henderson, I. G., Vickery, J. A. and Carter, N. (2004). The use of winter bird crops by farmland birds in lowland England. Biological Conservation. 118(1), 21-32. doi:10.1016/j.biocon.2003.06.003

Hof, A. R. and Bright, P. W. (2010). The impact of grassy field margins on macro-invertebrate abundance in adjacent arable fields. Agriculture, Ecosystems \& Environment. 139(1), 280-28. doi:10.1016/j.agee.2010.08.014

Holland, J., Smith, B., Storkey, J., Lutman, P. and Aebischer, N. (2015). Managing habitats on English farmland for insect pollinator conservation. Biological Conservation. 182(1), 215-222. doi:10.1016/j.biocon.2014.12.009

Holzschuh, A., Steffan-Dewenter, I., Kleijn, D. and Tscharntke, T. (2006). Diversity of flower-visiting bees in cereal fields: effects of farming system, landscape composition and regional context. Journal of Applied Ecology. 44(1), 41-49. doi:10.1111/j.1365-2664.2006.01259.x

Holzschuh, A., Dudenhoffer, J. H. and Tscharntke, T. (2012). Landscapes with wild bee habitats enhance pollination, fruit set and yield of sweet cherry. Biological Conservation. 153, 101-107. doi:10.1016/j.biocon.2012.04.032

Holzschuh, A., Dainese, M., Gonzalez-Varo, J. P., Mudri-Stojnic, S., Reidinger, V., Rundlof, M., Scheper, J., ... Steffan-Dewenter, I. (2016). Mass-flowering crops dilute pollinator abundance in agricultural landscapes across Europe. Ecology Letters. 19(10), 1228-1236. doi:10.1111/ele.12657

Jones, N. and Cheeseborough, I. (2014). A provisional atlas of the bees, wasps and ants of Shropshire. Telford: FSC Publications.

Kadala, A., Charreton, M., Charnet, P., Cens, T., Rousset, M., Chahine, M., Vaissiere, B. E. and Collet, C. (2019). Voltage-gated sodium channels from the bees Apis mellifera and Bombus terrestris are differentially modulated by pyrethroid insecticides. Scientific Reports. 9(1078). Doi: $10.1038 / s 41598-018-37278-z$ 
Klein, A., Vaissiere, B., Cane, J., Steffan-Dewenter, I., Cunningham, S., Kremen, C. and Tscharntke, T. (2007). Importance of pollinators in changing landscapes for world crops. Proceedings of the Royal Society B: Biological Sciences. 274(1608), 303-313. doi:10.1098/rspb.2006.3721

Kleijn, D., Rundlof, M., Scheper, J., Smith, G. H. and Tscharntke, T. (2011). Does conservation on farmland contribute to halting the biodiversity decline? Trends in Ecology \& Evolution. 26(9), 474-481. doi:10.1016/j.tree.2011.05.009

Kremen, C. (2015). Reframing the land-sparing/land-sharing debate for biodiversity conservation. Annals of the New York Academy of Science. 1355(1), 1-25. Doi: 10.1111/nyas.12845

Kremen, C., Williams, N. And Thorp, R. (2001). Crop pollination from native bees at risk from agricultural intensification. Proceedings of the National Academy of Sciences. 99(26), 1681216816. doi:10.1073/pnas.262413599

Landis, D. A. (2017). Designing agricultural landscapes for biodiversity-based ecosystem services. Basic and Applied Ecology. 18(1), 1-12. doi:10.1016/j.baae.2016.07.005

Larson, J. L., Dale, A., Held, D., McGraw, B., Richmond, D. S., Wickings, K. and Williamson, R. C. (2017). Optimizing pest management and practises to conserve pollinators in turf landscapes: Current practices and future research needs. Journal of Integrated Pest Management. 8(1), 1-10. doi:10.1093/jipm/pmx012

Liao, C, H., He, X. J., Wang, Z. L., Barron, A. B., Zhang, B., Zeng, Z. J. and Wu, X. B. (2018). Short-Term Exposure to Lambda-Cyhalothrin Negatively Affects the Survival and Memory-Related Characteristics of Worker Bees Apis mellifera. Archives of Environmental Contamination and Toxicology. 75(1), 59-65. Doi: 10.1007/s00244-018-0514-1

Mallinger, R. E., Gaines-Day, H. R. and Gratton, C. (2017). Do managed bees have negative effects on wild bees? A systematic review of literature. PLoS One. 12(12). Doi: 10.1371/journal.pone.0189268 
Marja, R., Kleijn, D., Tscharntke, T., Klein, A. M., Frank, T. and Batary, P. (2019). Effectiveness of agrienvironmental management on pollinators is moderated more by ecological contrast than by landscape structure of land-use intensity. Ecology Letters. 22(9), 1493-1500. doi:10.1111/ele.13339

Pamminger, T., Botias, C., Goulson, D. and Hughes, W. O. H. (2018). A mechanistic framework to explain the immunosuppressive effects of neurotoxic pesticides on bees. Functional Ecology. 32(8), 1921-1930. doi:10.1111/1365-2435.13119

Power, A. G. (2010). Ecosystem services and agriculture: tradeoffs and synergies. Philosophical Transactions of the Royal Society B. 365(1554), 2959-2971. doi:10.1098/rstb.2010.0143

Pollard, E. (1977). A method for assessing changes in the abundance of butterflies. Biological Conservation. 12(2), 115-134. doi:10.1016/0006-3207(77)90065-9

Pywell, R., Warman, E., Hulmes, L., Hulmes, S., Nuttall, P., Sparks, T., Critchley, C. and Sherwood, A. (2006). Effectiveness of new agri-environment schemes in providing foraging resources for bumblebees in intensively farmed landscapes. Biological Conservation. 129(2), 192-206. doi:10.1016/j.biocon.2005.10.034

Raymond, L., Sarthou, J. P., Plantegenest, M., Gauffre, B., Ladet, S. and Vialatte, A. (2014). Immature hoverflies overwinter in cultivated fields and may significantly control aphid populations in autumn. Agriculture, Ecosystems \& Environment. 185(1), 99-105. doi:10.1016/j.agee.2013.12.019

Rundlof, M., Nilsson, H. and Smith, H. G. (2008). Interacting effects of farming practice and landscape context on bumble bees. Biological Conservation. 141(2), 417-426. doi:10.1016/j.biocon.2007.10.011

Scheper, J., Holzschuh, A., Kuussaari, M., Potts, S. G., Rundlof, M., Smith, H. G. and Kleijn, D. (2013). Environmental factors driving the effectiveness of European agri-environmental measures in 
mitigating pollinator loss - a meta-analysis. Ecology Letters. 16(7), 912-920. doi:10.1111/ele.12128

Staley, J. T., Amy, S. R., Adams, N. P., Chapman, R. E., Peyton, J. M. and Pywell, R. F. (2015). Restructuring hedges: Rejuvenation management can improve the long term quality of hedgerow habitats for wildlife in the UK. Biological Conservation. 186(1), 187-196. doi:10.1016/j.biocon.2015.03.002

Stoate, C., Báldi, A., Beja, P., Boatman, N., Herzon, I., Van Doorn, A., De Snoo, G., Rakosy, L. and Ramwell, C. (2009). Ecological impacts of early 21st century agricultural change in Europe - A review. Journal of Environmental Management. 91(1), 22-46. doi:10.1016/j.jenvman.2009.07.005

Teixeira, H., Vermue, A., Cardoso, I., Peña Claros, M. and Bianchi, F. (2018). Farmers show complex and contrasting perceptions on ecosystem services and their management. Ecosystem Services. 33(Part A): 44-58. doi.org/10.1016/j.ecoser.2018.08.006

Van Klink, R., Boch, S., Buri, P., Rieder, N. S., Humbert, J. Y. and Arlettaz, R. (2017). No detrimental effects of delayed mowing or uncut grass refuges on plant and bryophyte community structure and phytomass production in low-intensity hay meadows. Basic and Applied Ecology. 20(1), 1-9. doi:10.1016/j.baae.2017.02.003

Vazquez, D. E., Ilian, N., Pagano, E. A., Zavala, J. A. and Farina, W. M. (2018). Glyphosate affects the larval development of honeybees depending on the susceptibility of colonies. PLOS ONE. 13(10). Doi: 10.1371/journal.pone.0205074

Westbury, D. B., Woodcock, B. A., Harris, S. J., Brown, V. K. and Potts, S. G. (2017). Buffer strip management to deliver plant and invertebrate resources for farmland birds in agricultural landscapes. Agriculture, Ecosystem \& Environment. 240(1), 215-223. doi:10.1016/j.agee.2017.02.031 
Whittingham, M. J. (2011). The future of agri-environment schemes: biodiversity gains and ecosystem service delivery? Journal of Applied Ecology. 48(3), 509-513. doi:10.1111/j.13652664.2011.01987.x

Wilson, J. S., Forister, M. L. and Carril, O. M. (2017). Interest exceeds understanding in public support of bee conservation. Frontiers in Ecology and the Environment. 15(8), 460-466. doi:10.1002/fee.1531

Wood, T., Holland, J., Hughes, W. and Goulson, D. (2015). Targeted agri-environment schemes significantly improve the population size of common farmland bumblebee species. Molecular Ecology. 24(8), 1668-1680. doi:/10.1111/mec.13144

Wood, T., Holland, J. and Goulson, D. (2017). Providing foraging resources for solitary bees on farmland: current schemes for pollinators benefit a limited suite of species. Journal of Applied Ecology. 54(1), 323-333. doi:10.1111/1365-2664.12718

Wratten, S. D., Gillespie, M., Decourtye, A., Mader, R. and Desneux, N. (2012). Pollinator habitat enhancement: Benefits to other ecosystem services. Agriculture, Ecosystems \& Environment. 159(1), 112-122. doi:10.1016/j.agee.2012.06.020 

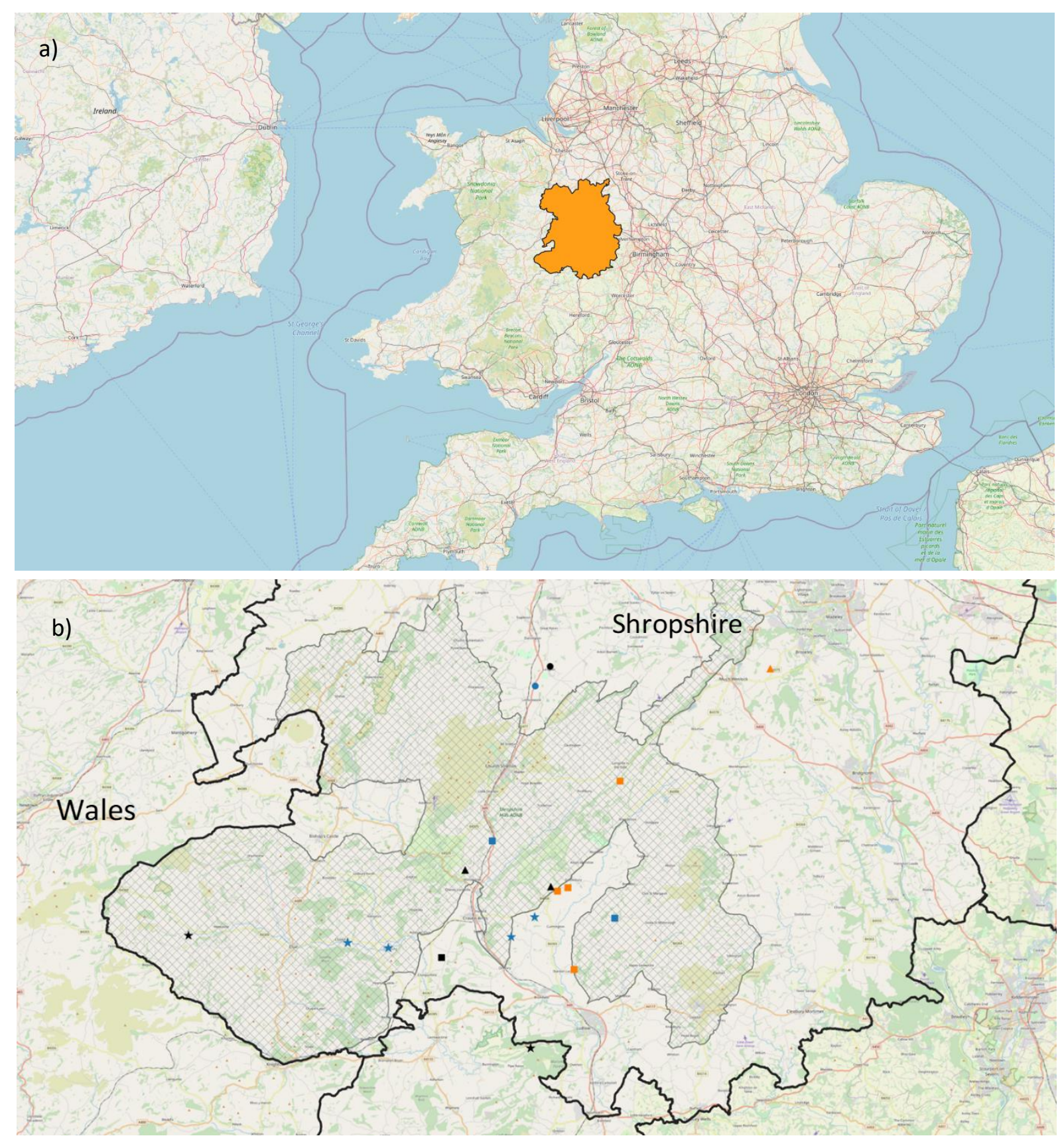

Fig. 1. Study site locations. a) orange indicates Shropshire county. b) black lines indicate county boundaries, grey hatching shows AONB. Colours indicate individual farms; blue=Conventional farms, orange=ELS farms, black=HLS farm. Shapes represent farm types; circle=Dairy, triangle=Arable, star=Livestock-based, square=Livestock-arable mixed. Created using QGIS 3.0.3, data sourced from MAGIC and Ordinance Survey. 


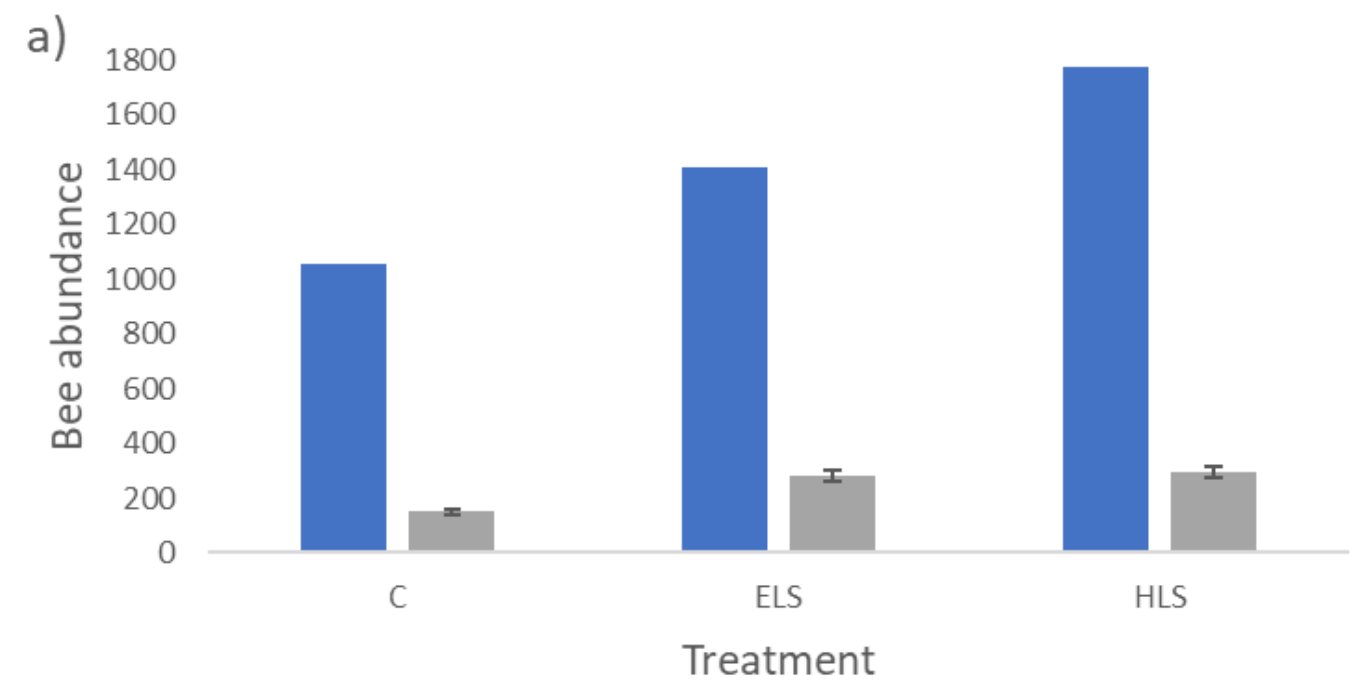

- Total bee sightings $\quad$ Mean sightings per farm

b) 60

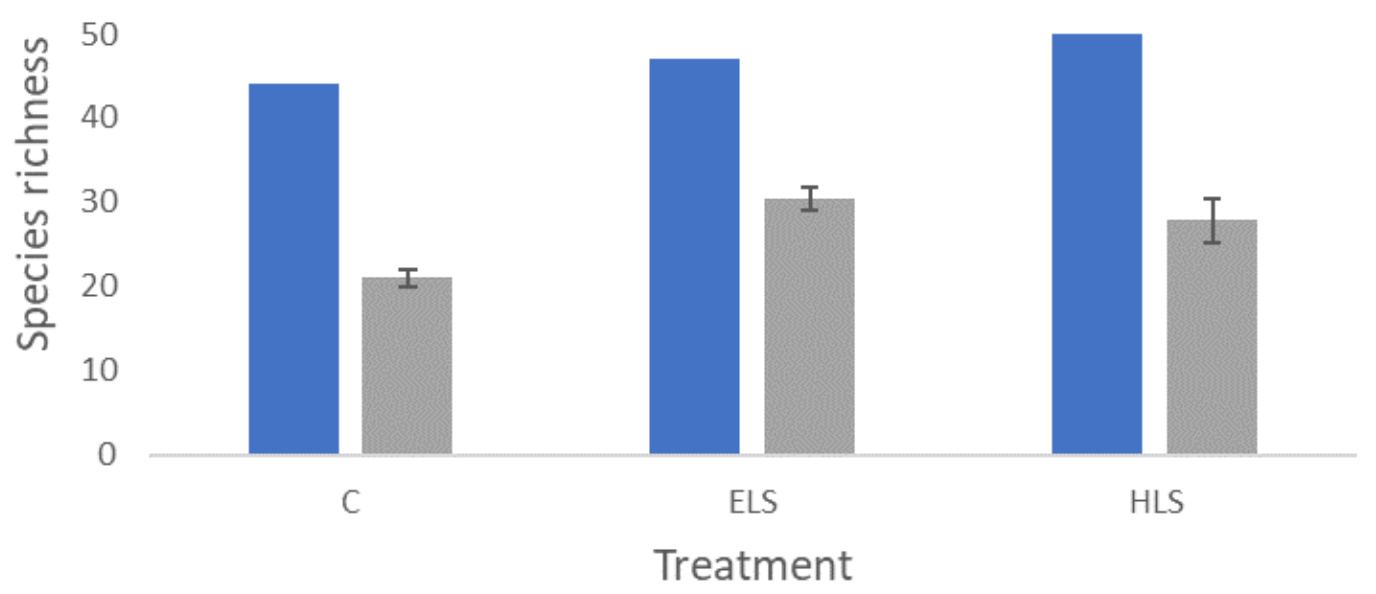

Total number of species Mean number of species

Fig. 2. Overall totals (blue) and means \pm se per survey (grey) of (a) bee abundance, and (b) species richness (HO) across the three treatment groups. C=conventional, ELS=entry-level stewardship, HLS=higher-level stewardship. 


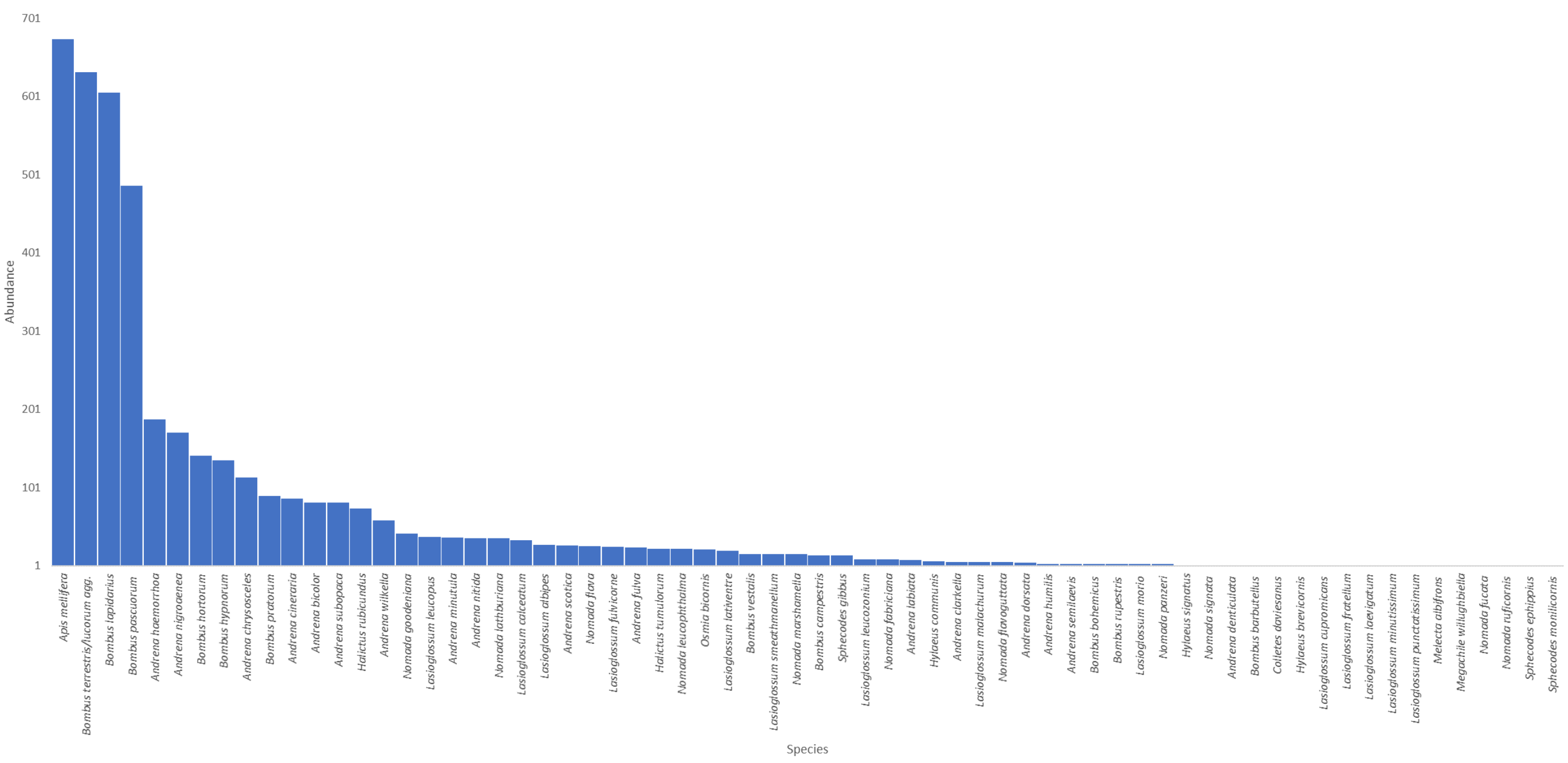

Fig. 3. Total abundance of all species identified throughout the entire study period. 


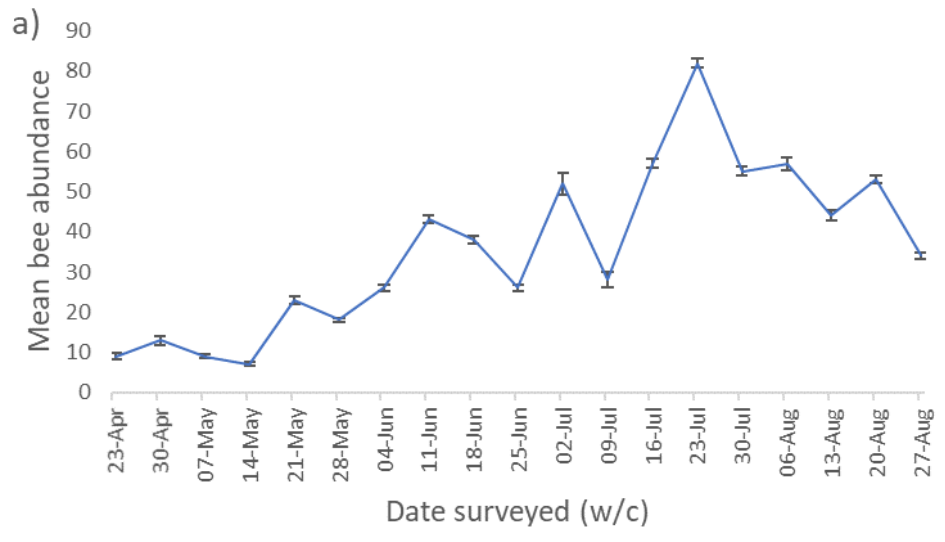

c)

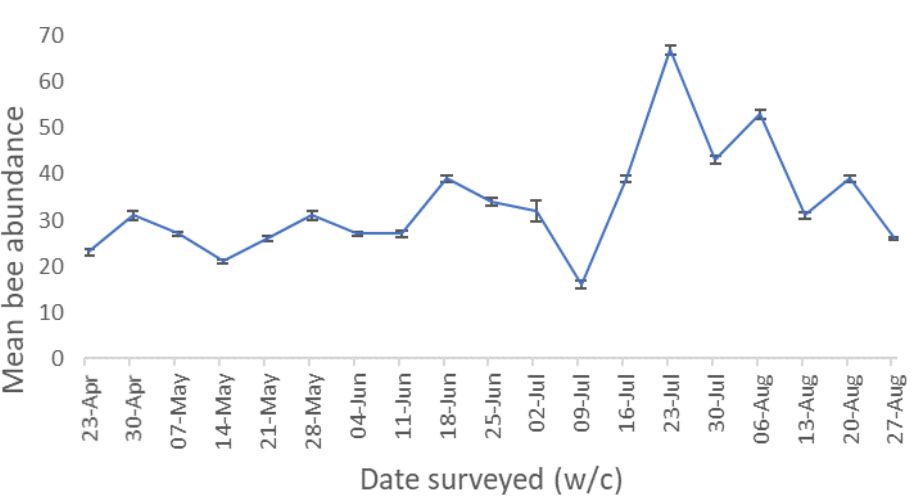

e) 30

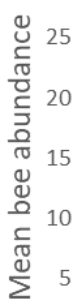

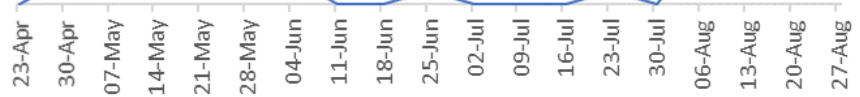
Date surveyed $(\mathrm{w} / \mathrm{c})$ b) 80

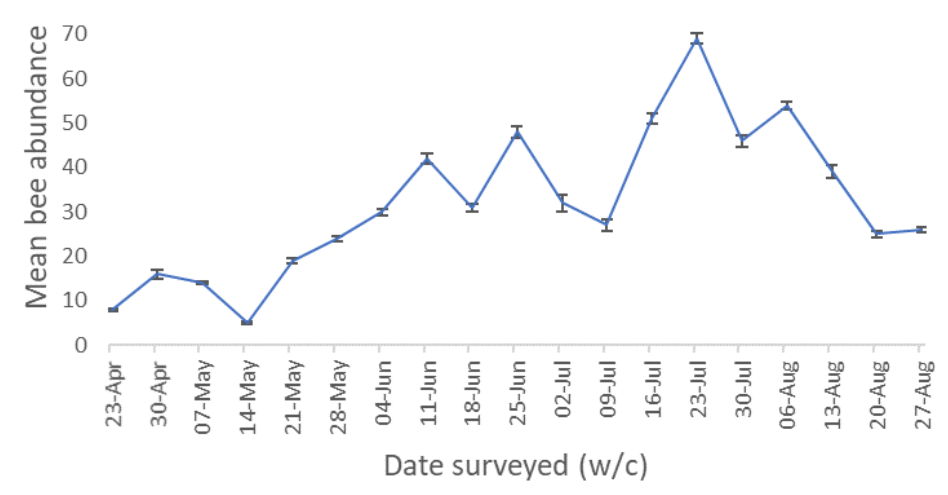

d) 45

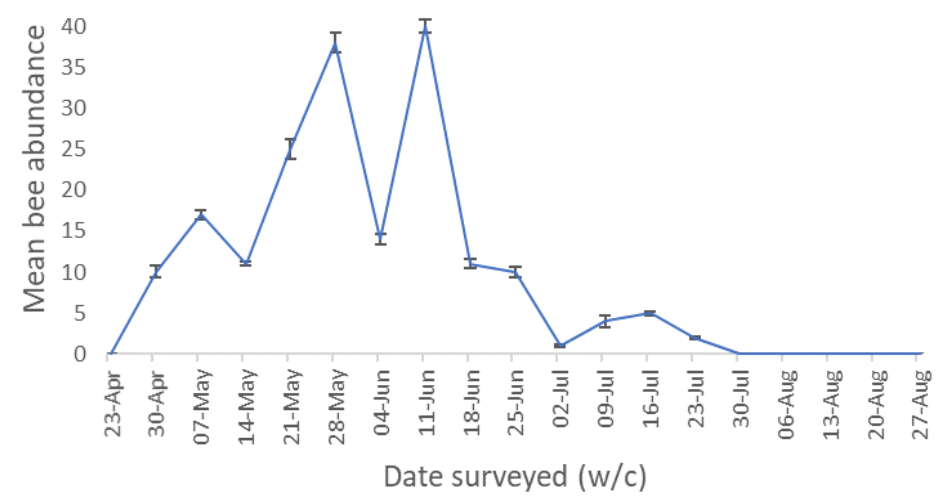

f) 14

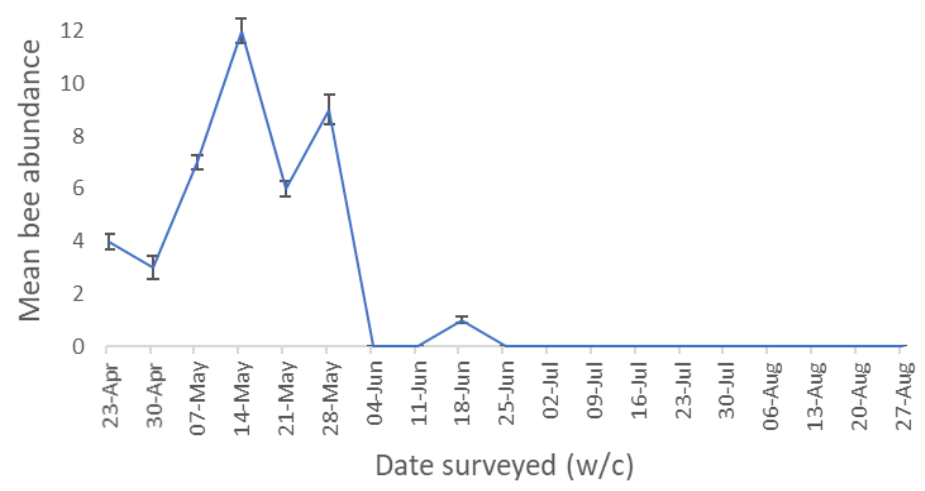

Fig. 4. Mean \pm se number of sightings through the season of a collection of common species. w/c=week commencing. a) Apis mellifera, b) Bombus lapidarius, c) Bombus terrestris/lucorum agg., d) Andrena heamorrhoa, e) Halictus rubicundus, f) Nomada goodeniana. 
a) 40

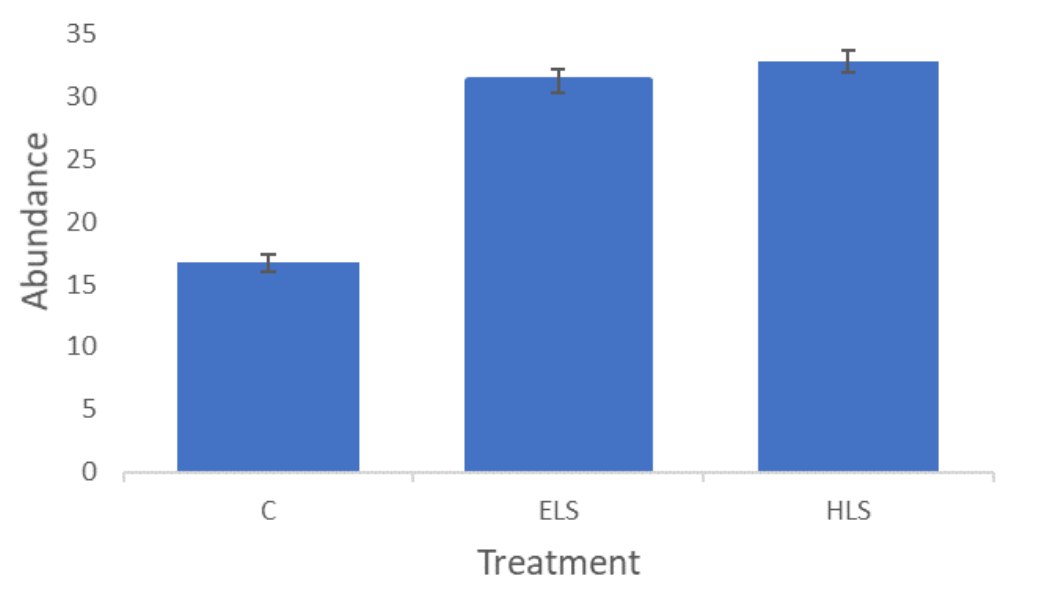

c)

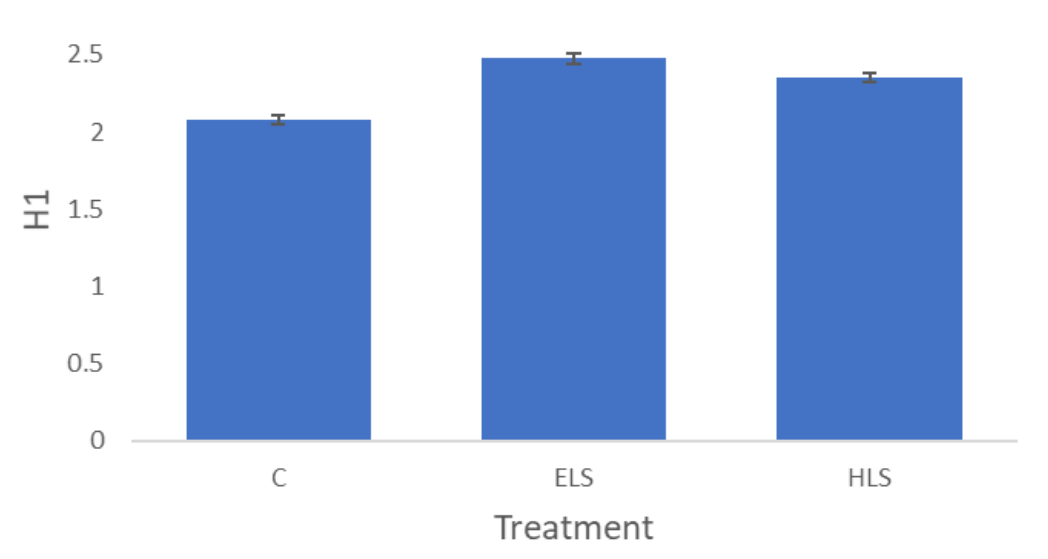

b) 12

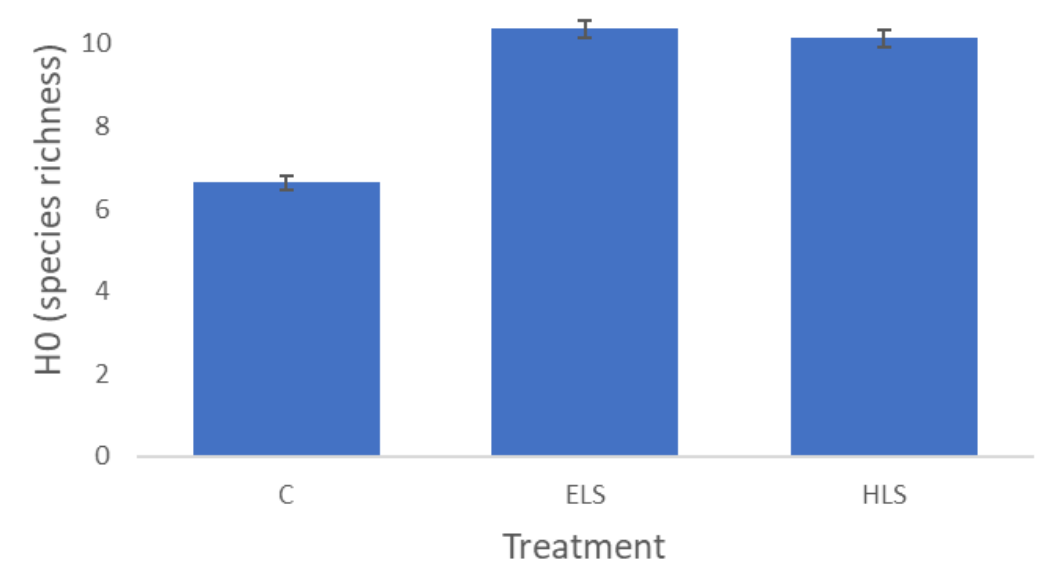

d)

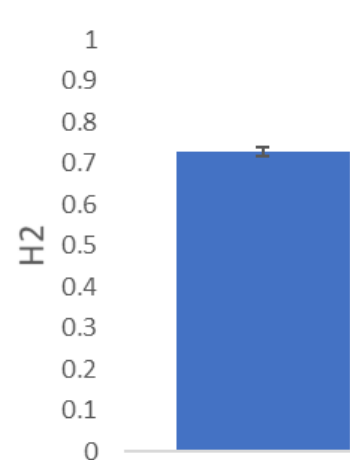

C

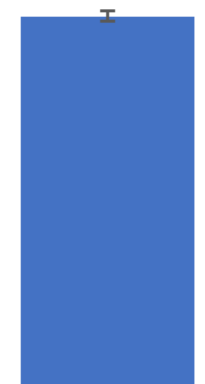

ELS

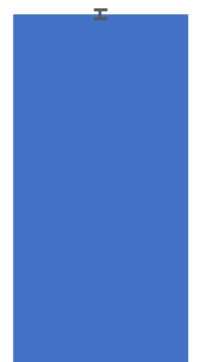

HLS
Treatment

Fig. 5. Marginal means \pm se per survey for each treatment group. a) bee abundance, b) Hill \#0 (species richness), c) Hill \#1 (abundant species), d) Hill \#2 (super abundant species). $C=$ conventional, ELS=entry-level stewardship, HLS=higher-level stewardship. 


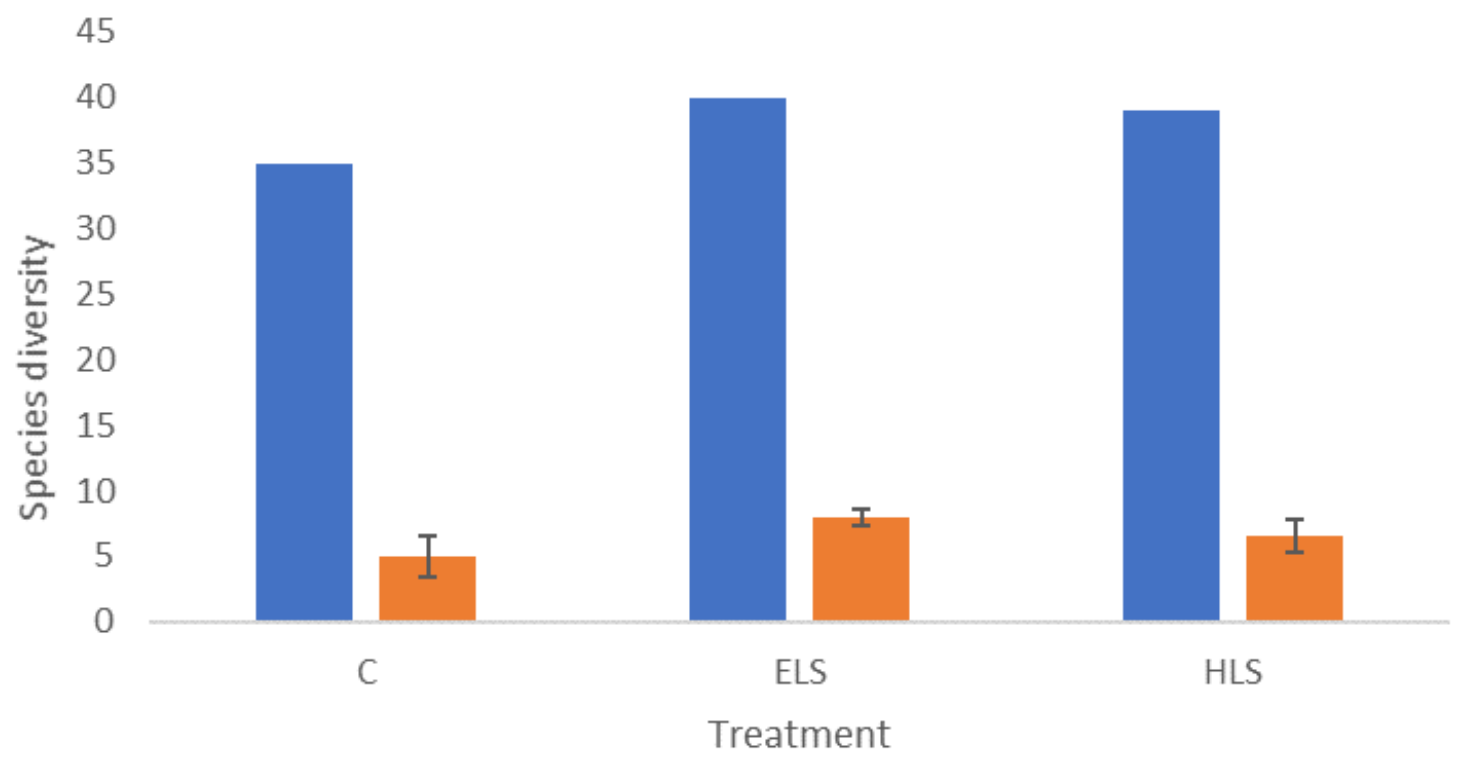

- Total number of species

Mean number of species

Fig. 6. Overall totals (blue) and means \pm se per survey (orange) of floral species diversity across the three treatment groups. $\mathrm{C}=\mathrm{conventional,} \mathrm{ELS=entry-level}$ stewardship, HLS=higher-level stewardship. 


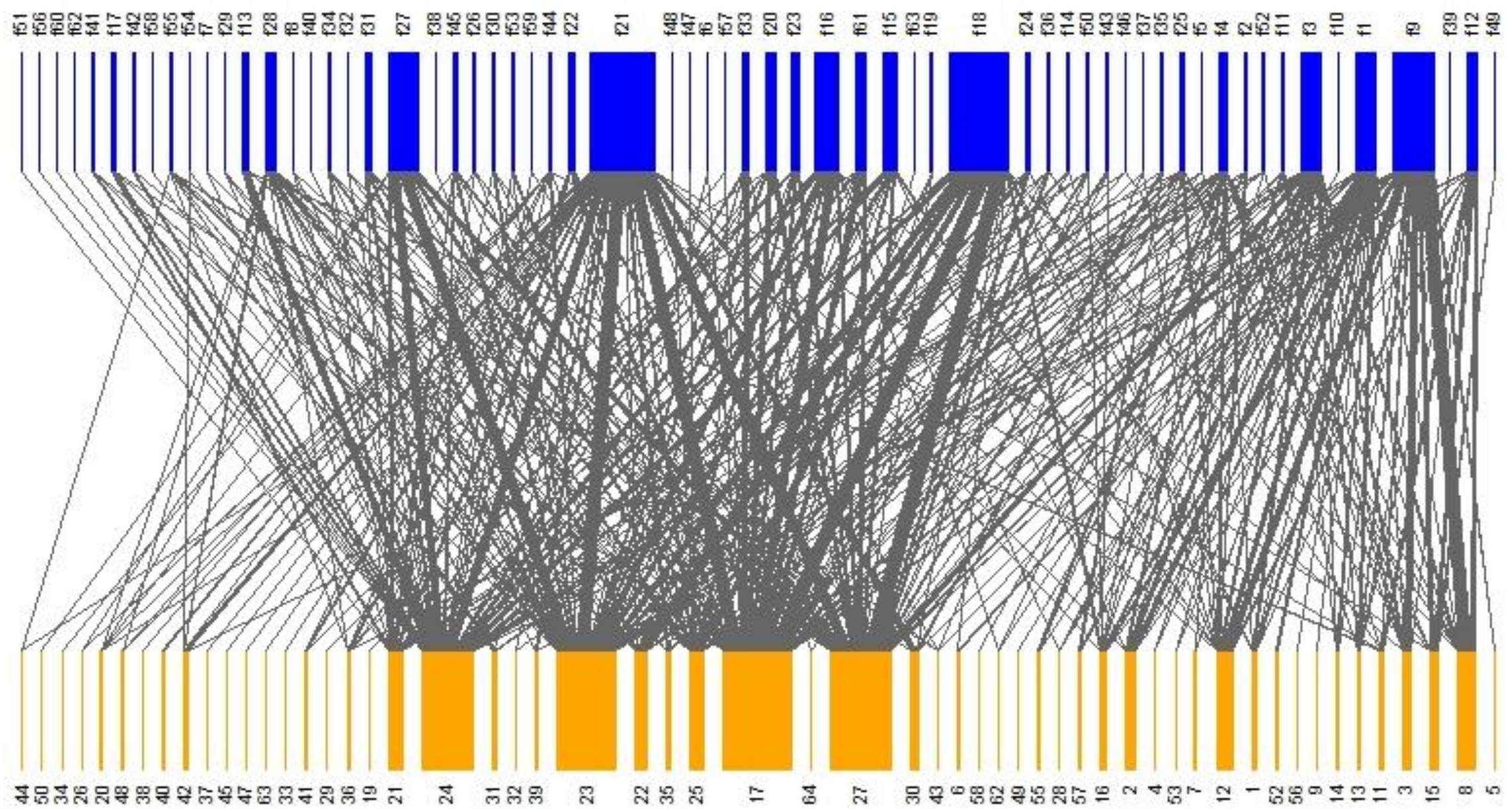

Fig. 7. Overall interactions between bees and flowers. The widths of orange (bee), blue (plant) and grey (interaction) nodes represent frequencies, and numbers refer to the listings in Tables S2 (bees) and S5 (plants). 17=Apis mellifera, 23= Bombus lapidarius, 24= B pascuorum, 27= B terrestris/lucorum agg., f9= Heracleum sphondylium, $\mathrm{f} 18=$ Rubus fruticosus, $\mathrm{f} 21=$ Cirsium arvense, $\mathrm{f} 27=C$ vulgare . 
